\title{
PRIMARY NON-HODGKIN LYMPHOMA OF SKELETAL MUSCLE COEXISTENCE WITH CUTANEOUS INFILTRATION
}

\author{
Ali Borazan ${ }^{1}$, Hasan Üstün ${ }^{2}$, Şamil Ecirli ${ }^{3}$ \\ Kocaeli University, Faculty of Medicine: Department of Internal Medicine ${ }^{1}$, Department of Medical Oncology²; Selcuk \\ University, Faculty of Medicine: Department of Internal Medicine ${ }^{3}$
}

Summary: This report describes a no-Hodgkin lyphoma case presenting with skeletal muscle and cutaneous involvement. A 75 year-old man was admitted to hospital with mass in the right upper extremity and skin lesions on the back of his trunk. Excisional mass biopsy was reported immunohistopthologically as large B-cell lymphoma. Primary extranodal lymphoma arising from skeletal muscle and concomitant skin infiltration of other body localization is not common. So this case was represented and relevant literature was reviewed.

Key words: Non-Hodgkin lymphoma; Skeletal muscle; Skin infiltration

Non-Hodgkin lymphoma (NHL) has heterogenous characteristics with clinical, histopathological and immunological features. NHL is seen more frequently in men than women. Extranodal involvement is more common in NHL than Hodgkin disease (6). Although stomach, small intestine, lung, breast, bone and central nervous systém is more common extranodal involvement sites with NHL, rare involvement sites are ovary, testis, prostat and kidney $(3,6$, $8,9)$. There is a few case reports with primary NHL in skeletal muscle in the literature (12). The skin might be involved in NHL both primrily site and also infiltration with nocules secondary to the disease (1).

We discribed a case with non-Hodgkin lymphoma of skeletal muscle presenting with nodule in the right upper extremity and coexistence of cutaneous infiltration at the back of his trunk.

\section{Case}

A 75 year-old male patient was admitted to the hospital on December 1999, with mass and discharge of serous-hemorrhagic fluid from the lesion of the right upper extremity, night sweating and body weight loss complaints. The patient had awared of 40x30 mm mass two months before admission to the hospital and the mass gradually became larger. The skin lesions were multiple in numbers, red-violet in color with irregular borders and elevated from skin at the back of trunk. The patient had a history of $10 \mathrm{~kg}$ body weight loss during 4 moths and fever and night sweating the last one week. At the admission physical examination of the patient's vital functions were as $130 / 70 \mathrm{mmHg}$ tension arterial pressure, $108 / \mathrm{min}$ pulse, $38.7{ }^{\circ} \mathrm{C}$ body temperature.
The red-violet skin lesions on the back of his trunk and 90x60 mm lesion in the right upper extremity were noticed. The other physical examination findings were found as normal. The laboratory findings of the patient were as follows: Hb: 1.5 g/1, Hct: $34.1 \%$, Leukocyte: $5.4 \times 10^{9} / 1$, Thrombocyte: $254 \times 10^{9} / 1$, erythrocyte sedimentation rate: $118 / \mathrm{mm} / \mathrm{hr}$, LDH: $1045 \mathrm{U} / \mathrm{L}$, albumin: $30 \mathrm{~g} / 1$, globulin: $30 \mathrm{~g} / 1$. The peripheral and bone marrow aspiration smears of the patient were evaluated as normal. Staphylococcus aureus that was sensitive to Co-trimoxasole, was detected from the lesion of upper extremity in the patient. Abdominal, thorax and cranial cumputed tomographies of the patient were normal. Both computed tomography and magnetic resonance imaging of the right upper eytremity of the patietn clarify solid mass with $85 \times 57 \mathrm{~mm}$ that was located anterolaterally to the humerus bone and between the muscles.

The mass excision biopsy of the patient was reported as high grade indifferentiated malignant lymphoma and tumor cells were found positive for CD20 and CDS45 immunohistopathologically. The findings were in consistent with aggressive large B cell lymphoma. The patient was diagnosed as extranodal non-Hodgkin lymphoma cutaneous involvement. He was treated with six courses of CHOP chemotherapy regimen. After the first course of treatment his cutaneous lesions were regressed. The patient in remission is still under clinical follow-up.

\section{Discussion}

The disease starts in extranodal sites of approximately ohne fourth of NHL cases (1). Hewever soft tissue as a primary site in NHL is not common $(2,6)$. This NHL case was 
reported because of skeletal muscle as primary site at the right upper extremity and coexistence of cutaneous infiltration of the other part of body with the disease.

The case series of primary NHL in ovary (8), prostat (3), kidney (9) and skeletal muscle $(1,2,4,7,11,12,13)$ were reported in the literature. Sumuel et al. Reported eight cases with NHL diagnosis involving primarily upper extremity and gluteus region during 15 years (12). Bertoni et al. Reported four cases with primary skeletal muscle NHL (2). Luraschi et al. (7) and also a few authors reported single case presentations with primary skeletal muscle NHL in the literature. The most number case in regard to skeletal muscle NHL was reported by Salamao and coworkers (11). They reported from Mayo Clinic, 19 cases with NHL of primary skeletal muscle or skin. The involvement sites were counted as: seven lower extremity, six upper extremity, three chest wall, two gluteal region and one subgaleal region. Twelve out of 19 cases were reported as high grade lymphoma. Our case's pathology was also as indifferentiated high grade lymphoma. Travis and coworkers reported eight cases out of 7000 with NHL of primary site as extremity with diagnosis of malignant lymphoma during 10 years (13). The primary involvement sites od upper and lower extremity were reported as 2 and 6 numbers. Both Salamao and Travis reported less common involvement as primary site for upper extremity with NHL. Our case had skeletal muscle NHL in the right upper extremity.

Chim and coworkers reported a case with compartment syndrome due tu NHL of skeletal muscle in upper extremity (4). In our case swelling and serous-hemorrhagic discharge were seen from lesion of right upper extremity but no compartment syndrome findings.

In the differential diagnosis of primary upper extremity NHL, sarcomas, metastatic carcinomas and malignant melanomas are found and their radiological appearances are similar (2). In our case computed tomography and magnetic resonance imagings of the upper extremity were reported as soft tissue sarcoma.

The skin lymphomas other than mycosis fungoides are rare and skin infilration is generally regarded as a sign of disease progression in NHL (5). The diagnosis of skin lymphomas other than mycosis fungoides should be confirmed immuno-histopathologically (10). In our case the skin involvement was observed after the right upper extremity swelling and this finding was suggested as disease progression. So we did not need to confirm the diagnosis of skin lesion.

In the literature the extremity lymphomas were reported as unifocal lymphoid masses and authors propose the treatment as radiotherapy or tadiotherapy and chemotherapy (7). The CHOP chemotherapy regimen might be used with or withour radiotherapy in the reatment of large cell lymphoma (2). The CHOP chemotherapy regimen was given to the patient and after the first course of treatment the lesions on his trunk almost diappeared and six courses of the treatment was completed without any complication. The patient is still alive and followed without any problem in regard to the disease.

As a conclusion the extremity lesions should be explored carefully. All laboratory tests and especially immuno-histopathological examination must be evaluated before the final diagnosis. After the diagnosis, properly designed treatment might achieve good results in cases with NHL of extremity skeletal muscle.

\section{References}

1. Ashwort J, Coady AT, Guy R et al. Browny cutaneous induration and granulomatous panniculitis in large cell non-Hodgkin's (Tsupressor/cytotoxic cell) lymphoma. Br J deramtol 1989;120:563-9.

2. Bertoni F, Sanna P, zucca E et al. Primary extranodal lymphoma of skeletal muscles: A report of four cases. Oncol Rep 1998;5:605-7.

3. Botswich DG, Lezkowski KA, Amin MB et al. Malignant lymphoma involving ghe prostate: Report of 62 cases. Cancer 1998;75:2258-61

4. Chim CS, Choy C, Liang R. primary anaplastic large cell lymphoma of skeletal muscle presenting with compartment syndrome. Leuk Lymphoma 1999;33: 601-5.

5. Chimenti S, Fink-Puches R, Peris K et al. Cutaneous involvement in lypholastic lymphoma. J Cutan Pathol 1999;26:379-85.

6. Harris NL, jaffe ES, Diebold J et al. Lymphoma classification from controversy to consensus: the R.E.A.L. and WHO Classification of lymphoid neoplasms. Ann Oncol 2000;11(Suppl.1):3-10.

7. Luraschi A, Saglietti G, Ferrari V et al. Primary extranodal non-Hodgkin's lymphoma of muscle tissue. Recenti Prog Med 1997;88:166-8.

8. Monterosso V, jaffe ES, Merino MJ et al. Malignant lymphoma invoving the ovary. A clinicopathologic analysis of 39 cases. Am J Surg Pathol 1993;17:154-70.

9. Okuna SH, Hoyer JD, Ristow K et al. Primary renal non-Hodgkin's lymphoma An unusual extranodal site. Cancer 1985;75:2258-61.

10. Rijaarsdam JU, Willemze R. primary cutaneous B-cell lymphoma. Leuk Lymphoma 1994;14:213-8.

11. Salamao DR, Nascimento AG, Lloyd RV et al. Lymphoma in soft tissue; A clinicopathologic study of 19 cases. Hum Pathol 1997;11:359-66.

12. Samuel LM, White J, Lessells AM et al. Primary non-Hodgkin lymphoma of muscle. Clin Oncol (R Coll Radiol) 1999;11:49-51.

13. Travis WD, Banks PM, Reiman HM. Primary extranodal soft tissue myphoma of the extremities. Am J Surg Pathol 1997;11:359-66.

Submitted March 2003.

Accepted August 2003.

Hasan Üstün, M.D., Harpsundsvägen 9, 2tr, 12458 Bandhagen/Stockholm, Sweden. e-mail: ustunhtr@hotmail.com 